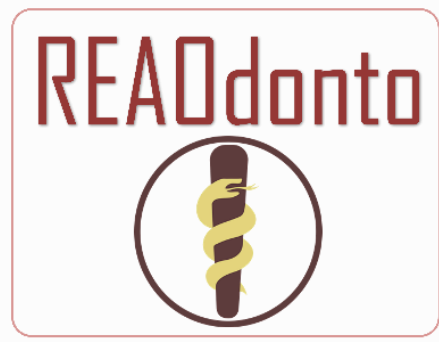

Revista Eletrônica

Acervo Odontológico

\section{ESTUDO DE CASO}

Recebido em: 11/2020

Aceito em: $11 / 2020$

Publicado em: 12/2020

\title{
Levantamento de seio maxilar bilateral por duas técnicas diferentes com concomitante instalação de implantes: relato de caso
}

\author{
Bilateral maxillary sinus lift by two different techniques with concomitant installation the \\ implants: case report

\section{Elevación bilateral del seno maxilar mediante das técnicas diferentes con instalación concomitante de implantes: reporte de caso}

Sayene Garcia Batista ${ }^{1 *}$, Myllena Raposo Santana de Faria1 ${ }^{1}$, Jeter Bochnia1, Osmar de Agostinho Neto ${ }^{1}$, Elson Braga de Mello ${ }^{1}$, Clarissa Bichara Magalhães ${ }^{1}$.

\begin{abstract}
Resumo: Esse artigo buscou demonstrar, através de um relato de caso clínico, a abordagem de levantamento de seio maxilar bilateral por duas diferentes técnicas, uma traumática via janela lateral e uma atraumática através da crista óssea, associadas à instalação de implantes osseointegrados. Paciente com 75 anos, gênero feminino procurou atendimento na clínica do Curso de Extensão em Implantodontia em uma universidade do Rio de Janeiro com quadro álgico em região de molares superiores. Após anamnese, exame clínico e análise da tomografia computadorizada, evidenciou-se extensa lesão de furca nos elementos 16 e 26, sendo indicada exodontia e reabilitação com implantes oseeointegrados. Ainda, devido à pouca altura óssea subantral, o levantamento de seio maxilar bilateral foi incluído ao plano de tratamento. No lado direito, foi realizada a técnica de Summers e no lado esquerdo a técnica da janela lateral associada ao uso de biomaterial sintético particulado e membrana de colágeno reabsorvível. A radiografia panorâmica de controle pós-cirúrgico demostrou o êxito das duas técnicas com adequada relação anatômica do enxerto e de ambos os implantes ao leito receptor. Assim, a cirurgia de elevação do seio maxilar com a concomitante instalação de implantes se mostrou um procedimento seguro, de boa previsibilidade e baixa taxa de complicações.
\end{abstract}

Palavras-chave: Atrofia, Levantamento do assoalho do seio maxilar, Implantes dentários.

\begin{abstract}
This article aims to demonstrate, through a clinical case report, the bilateral maxillary sinus lifting approach by two different techniques, a traumatic one through the side window and an atraumatic one through the bone crest, associated with the installation of osseointegrated implants. A 75-year-old female patient sought care at the clinic of the Extension Course in Implantology at an university of Rio de Janeiro with pain in upper molars. After anamnesis, clinical examination and analysis of computed tomography, extensive furcation lesion was observed in elements 16 and 26, with extraction and rehabilitation with oseeointegrated implants being indicated. Also, due to the low subantral bone height, the lifting of the bilateral maxillary sinus was included in the treatment plan. On the right side, the Summers technique was performed and on the left side the side window technique associated with the use of particulate synthetic biomaterial and resorbable collagen membrane. The panoramic radiograph of post-surgical control demonstrated the success of both techniques with an adequate anatomical relationship of the graft and both implants to the recipient bed. Thus, maxillary sinus elevation surgery with the concomitant installation of implants proved to be a safe procedure of good predictability and low rate of complications.
\end{abstract}

Keywords: Atrophy, Sinus floor augmentation, Dental implants.

\footnotetext{
1 Universidade Federal do Rio de Janeiro (UFRJ), Rio de Janeiro - RJ.

*E-mail: sayenegarciabatista@gmail.com
} 
Resumen: Este artículo pretende demostrar, a través de un caso clínico, el abordaje de elevación bilateral del seno maxilar mediante dos técnicas diferentes, una traumática a través de la ventana lateral y otra atraumática a través de la cresta ósea, asociada a la instalación de implantes osteointegrados. Paciente de sexo femenino de 75 años que acude a la clínica del Curso de Extensión en Implantología en una universidad de Río de Janeiro por dolor en molares superiores. Tras anamnesis, exploración clínica y análisis de tomografía computarizada, se observó lesión extensa de furca en los elementos 16 y 26, estando indicada la extracción y rehabilitación con implantes oseeointegrados. Además, debido a la baja altura del hueso subantral, el levantamiento del seno maxilar bilateral se incluyó en el plan de tratamiento. En el lado derecho se realizó la técnica de Summers y en el lado izquierdo la técnica de ventana lateral asociada al uso de biomaterial sintético particulado y membrana de colágeno reabsorbible. La radiografía panorámica de control postquirúrgico demostró el éxito de ambas técnicas con una adecuada relación anatómica del injerto y ambos implantes con el lecho receptor. Así, la cirugía de elevación del seno maxilar con la instalación concomitante de implantes demostró ser un procedimiento seguro, de buena previsibilidad y baja tasa de complicaciones.

Palabras clave: Atrofia, Elevación del piso del seno maxilar, Implantes dentales.

\section{INTRODUÇÃO}

A quantidade adequada de altura óssea é uma condição essencial para a reabilitação na Implantodontia. Nesse contexto, atrofia óssea e a pneumatização do seio maxilar, associados a baixa densidade óssea dessa região, proporciona local inapropriado para a instalação e manutenção de implantes osseointegrados (BASSI AP, et al., 2015). Em tal situação, propõe-se o procedimento de levantamento ou elevação do seio maxilar, o qual objetiva aumentar a altura de osso residual na maxila posterior através da elevação da membrana de Schneider e, consequentemente, do assoalho do seio maxilar.

Desta forma, o ganho de altura óssea possibilita a instalação e o posicionamento adequado dos implantes dentários osseointegrados (AL-DAJANI M, 2014). Este procedimento, por sua vez, pode ser realizado por meio de diferentes técnicas, traumática ou atraumática, utilizando biomaterial ou não, com instalação concomitante ou posterior do implante dental (BASSI AP, et al., 2015; AL-DAJANI M, 2014; CHIPAILA N, et al., 2014).

Atualmente, são conhecidas as duas abordagens cirúrgicas usadas para o manejo da maxila posterior atrófica: a técnica da janela lateral / abordagem direta e a técnica do osteótomo transcrestal / abordagem indireta (AL-DAJANI M, 2014). Em 1975, Tatum introduziu pela primeira vez o procedimento pela técnica da janela lateral (técnica traumática) que foi modificado e detalhado por Boyne e James em 1980 (SILVA LD, et al., 2016; PARRA M, et al., 2018).

Incialmente, o procedimento cirúrgico foi descrito em duas sucessivas etapas: a primeira, consistente na realização da abertura de uma janela na parede lateral do seio maxilar, e a segunda, na elevação da membrana de Schneider (AL-DAJANI M, 2014). Para isso, após incisão da mucosa gengival e exposição óssea, realiza-se uma osteotomia na parede lateral do seio maxilar até que este fragmento ósseo possa ser destacado e elevado apical e medialmente junto à membrana sinusal, a qual deve ser cuidadosamente descolada. Por fim, um material de enxertia pode ser inserido na cavidade criada para preenchimento desta e auxílio na neoformação óssea. A cirurgia de elevação do seio é geralmente seguida de enxertia óssea para preencher o compartimento criado entre o assoalho ósseo do seio maxilar e a membrana de Schneider (CHIPAILA N, et al., 2014; CORBELLA S, et al., 2015; TASCHIERI S, et al., 2012; CARA-FUENTES M, et al., 2016).

Na década de 90, Summers aperfeiçoou a abordagem e descreveu um método atraumático de elevação do assoalho do seio maxilar conhecido como a técnica do osteótomo transcrestal. A cirurgia atraumática de levantamento do seio maxilar é menos invasiva, mas exige treinamento de materiais específicos para a realização de uma elevação transalveolar do assoalho do seio maxilar (AL-DAJANI M, 2014).

Após a perfuração do rebordo alveolar com fresas do sistema de implante a ser utilizado, realiza-se uma compactação da massa óssea próxima à cortical da cavidade sinusal com auxílio de um osteótomo até que a membrana sinusal seja elevada juntamente com assoalho do seio maxilar fraturado. 
Desta forma, ocorre manutenção de osso sobre a ponta ativa dos osteótomos durante o seu deslocamento para apical, o qual será repetido de acordo com o planejamento, seguindo a sequência dos osteótomos com diâmetros crescentes (CHIPAILA N, et al., 2014; CARA-FUENTES M, et al., 2016; RAJA SV, 2009). A maxila posterior atrófica pode-se apresentar como um grande desafio para a implantodontia. A dificuldade mais evidente encontra-se no estado anatômico que é caracterizado por uma qualidade óssea menos favorável e insuficiente volume ósseo resultantes da pneumatização do seio maxilar e da reabsorção da crista alveolar.

Assim, esta é uma condição clínica que pode ser corrigida com o procedimento de levantamento do assoalho do seio maxilar, através das diferentes técnicas cirúrgicas disponíveis. Esse artigo buscou demonstrar, através de um relato de caso clínico, a abordagem de levantamento de seio maxilar bilateral por duas diferentes técnicas, uma traumática via janela lateral e uma atraumática através da crista óssea, associadas à instalação de implantes osseointegrados.

\section{DETALHAMENTO DO CASO}

Paciente do gênero feminino, 75 anos, procurou à clínica do Curso de Extensão em Implantodontia em uma universidade do Rio de Janeiro com quadro álgico em região de molares superiores. Com a realização da anamnese e do exame clínico, associada a análise da tomografia computadorizada, evidenciou-se extensa lesão de cárie e comprometimento de furca nos dentes 16 e 26, além de pouco remanescente ósseo apical na região (Figura 1). Para a resolução do caso e reabilitação, o plano de tratamento delineado envolveu a exodontia dos dentes 16 e 26, a elevação do seio maxilar na região, utilizando a técnica indireta no lado esquerdo e técnica direta no lado direito, além da instalação imediata de implantes osseointegrados.

Figura 1 - Tomografia computadorizada pré-operatória.

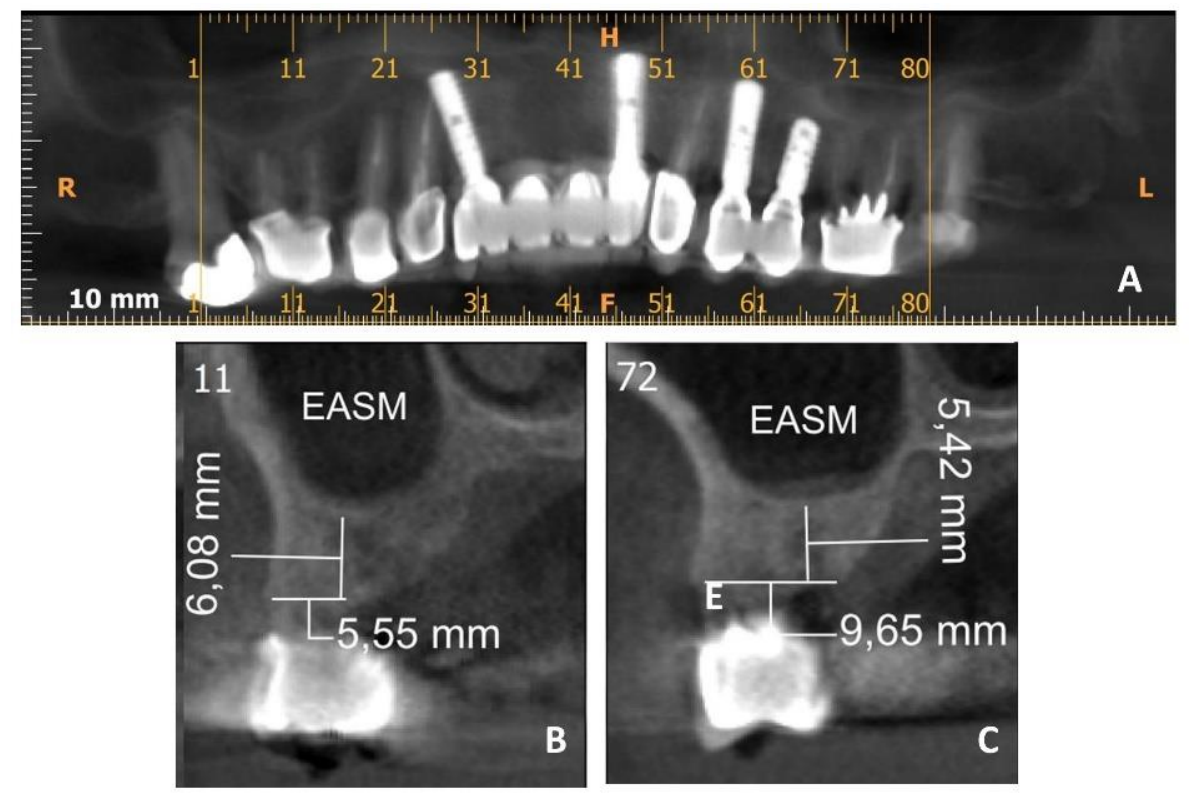

Legenda: Corte panorâmico (A) e cortes transversais das regiões dos elementos 16 (B) e 26 (C). Fonte: BATISTA SG, et al., 2020.

A elevação do seio maxilar direito foi realizada pela técnica de Summers. A técnica cirúrgica foi conduzida sob anestesia local com articaína 4\% e epinefrina 1:100.000 (DFL Indústria e Comércio S.A) (Figura 2). Logo após a exodontia simples do dente 16 , a fresagem inicial foi realizada na região do septo interradicular no limite de $2 \mathrm{~mm}$ aquém do soalho do seio maxilar com uma broca lança.

Posteriormente, a fresa helicoidal 2.0 foi introduzida até o limite preestabelecido na perfuração inicial, sendo este alargamento do alvéolo importante para a adaptação do osteótomo. O osteótomo de diâmetro ligeiramente maior que esta perfuração foi adaptado ao alvéolo cirúrgico, auxiliado por um martelo, para a 
introdução deste no sentido corono-apical até ultrapassar o limite de modo a promover uma fratura do assoalho do seio maxilar. Seguidamente, foi instalado o implante cone morse 3,8 x 8,5 mm CM Strong SW $\operatorname{SIN}^{\circledR}$ (SIN Sistema de Implante, São Paulo, Brasil) com torque de inserção de $40 \mathrm{Ncm}$.

Figura 2 - Sequência de elevação de seio maxilar pela técnica de Summers.
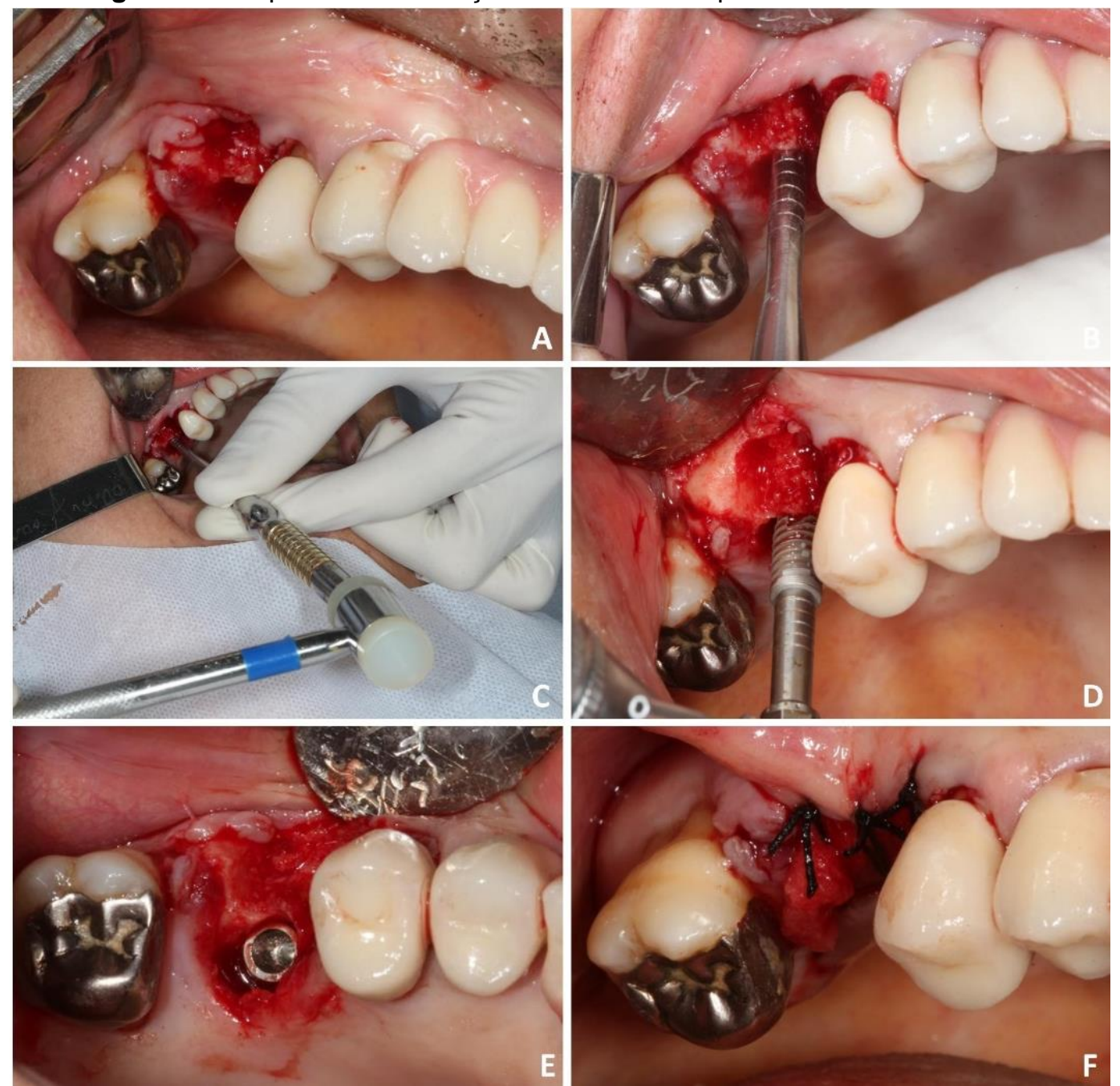

Legenda: Alvéolo cirúrgico pós-exodontia do elemento 16 (A); posicionamento do osteótomo (B); introdução do osteótomo no sentido corono-apical com auxílio de um martelo (C); instalação do implante (D); verificação do posicionamento do implante instalado $(E)$; sutura em pontos simples interrompidos $(F)$.

Fonte: BATISTA SG, et al., 2020.

No lado esquerdo, que apresentava altura óssea subantral ligeiramente menor, além de uma imagem mais hipodensa, executou-se a técnica da janela lateral.

Foi realizado o mesmo procedimento anestésico que no lado direito, seguido da exodontia simples do dente 26 e incisão sobre a crista mais relaxante na distal do dente 25. Após o descolamento mucoperiosteal de espessura total, o desgaste da parede lateral do seio maxilar foi executado com broca esférica diamantada sob irrigação abundante, de maneira a expor a membrana de Schneider. Então, o osso foi removido cuidadosamente até ser evidenciada a membrana sinusal, evitando pressão excessiva. Posteriormente, 0 descolamento e a elevação da membrana de Schneider foram executados com curetas anguladas específicas, desinserindo a região do soalho e circundando toda a janela lateral, para criar o espaço necessário e preencher a cavidade com biomaterial (Figura 3). 
Figura 3 - Sequência de levantamento de seio pela técnica da janela lateral.

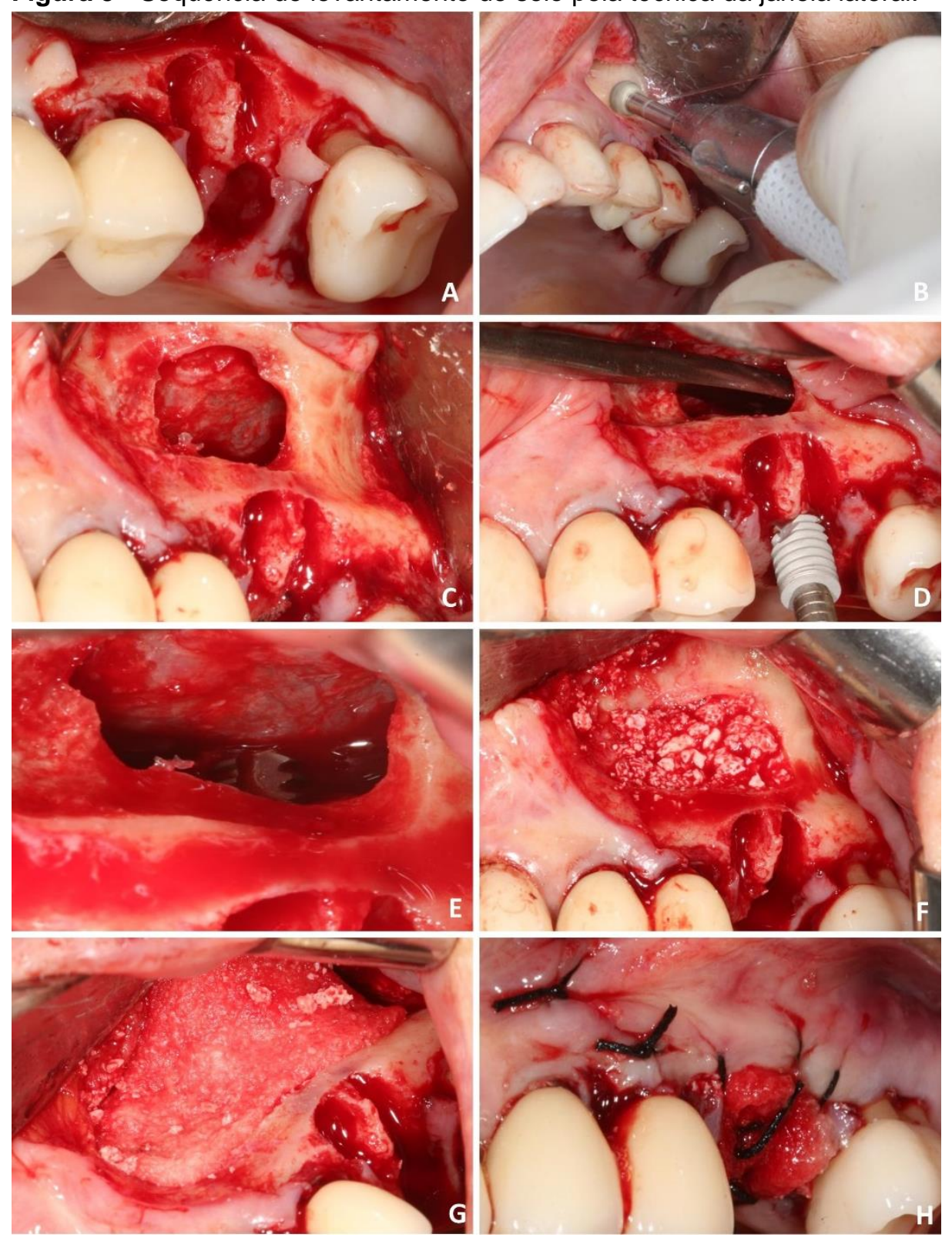

Legenda: Alvéolo cirúrgico pós-exodontia do elemento 26 (A); abertura da janela lateral (B); membrana de Schneider descolada (C); instalação do implante (D); implante instalado e sua relação delicada com a membrana sinusal elevada (E); finalização do preenchimento da janela com biomaterial sintético particulado $(F)$; recobrimento da janela com membrana de colágeno reabsorvível $(G)$, sutura em pontos simples interrompidos $(H)$.

Fonte: BATISTA SG, et al., 2020.

O ato contínuo foi a fresagem do leito cirúrgico alveolar, seguindo a sequência de brocas do sistema de implante. Finalizado o preparo do alvéolo cirúrgico, o preenchimento com o biomaterial sintético particulado Bio-Oss $^{\circledR}$ (Geistlich Biomaterials, Wolhuser, Suíça) foi realizado, realizando-se sucessivamente a instalação do implante cone morse 4,5 x 10 mm CM Strong SW SIN ${ }^{\circledR}$ (SIN Sistema de Implante, São Paulo, Brasil) com torque de inserção de $40 \mathrm{Ncm}$. Finalmente, após o preenchimento de toda cavidade com o biomaterial, foi adicionada sobre a janela uma membrana de colágeno reabsorvível Surgidry (Technodry, Belo Horizonte, Brasil). O procedimento cirúrgico se encerrou com reposicionamento do retalho e realização de suturas simples. Ao final dos atos cirúrgicos, uma radiografia panorâmica de controle pós-operatório foi solicitada, a 
qual revelou os assoalhos dos seios maxilares elevados como planejado e o adequado posicionamento dos implantes (Figura 4).

Figura 4 - Radiografia panorâmica pós-operatória.

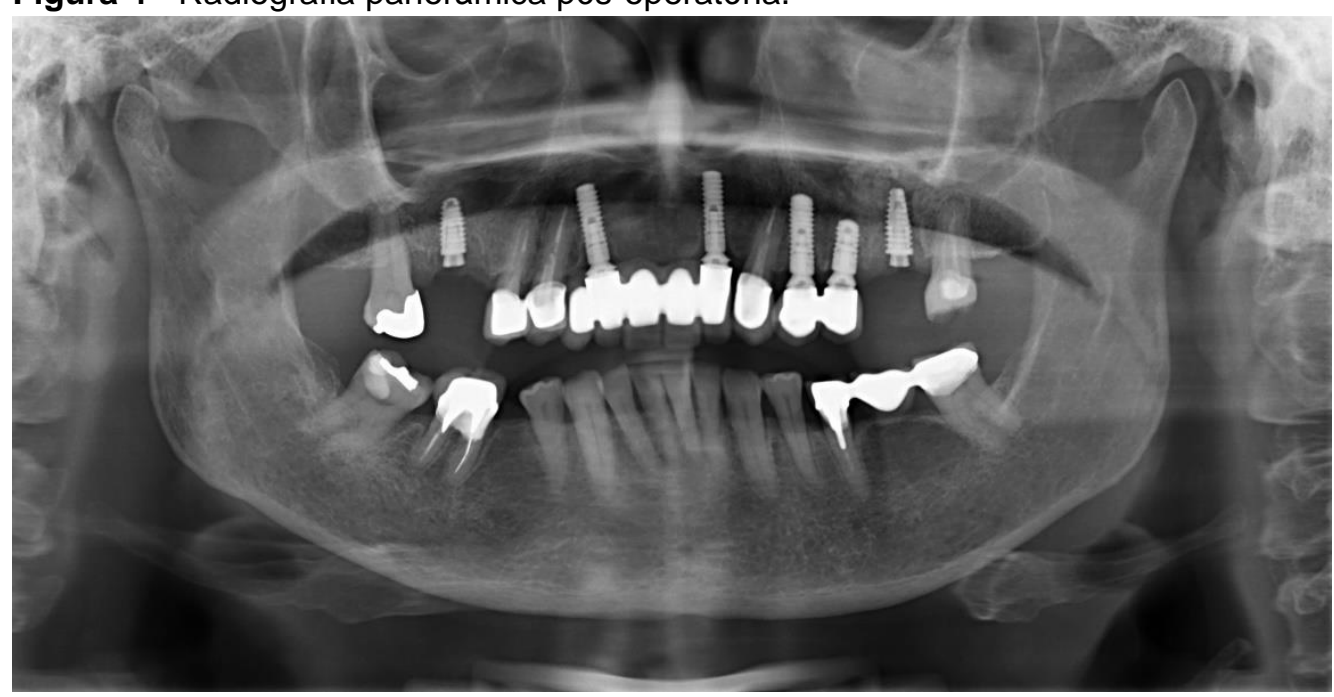

Legenda: Implantes instalados nas regiões de 16 e 26.

Fonte: BATISTA SG, et al., 2020.

\section{DISCUSSÃO}

A pneumatização do seio maxilar pode reduzir significativamente a altura do osso alveolar. As cirurgias de elevação do assoalho do seio maxilar são indicadas na ausência de altura óssea suficiente que possa impedir ou dificultar a instalação de implantes na região posterior maxilar (CARA-FUENTES M, et al., 2016). A elevação do seio maxilar, independentemente do método, é executada, com alto índice de sucesso, como um procedimento de rotina (SILVA LD, et al., 2016).

A escolha da abordagem está relacionada com a quantidade de osso alveolar remanescente. Em casos de altura óssea residual superior a $5 \mathrm{~mm}$, a abordagem pela técnica do osteótomo transcrestal é geralmente indicada; já quando a altura óssea residual for de $5 \mathrm{~mm}$ ou menos, a abordagem da janela lateral é mais indicada, por possibilitar maior ganho de altura óssea (CORBELLA S, et al., 2015; CARA-FUENTES M, et al., 2016; PARRA M, et al., 2018). No caso apresentado no presente artigo, foi escolhida a técnica de Summers para lado direito, cuja altura óssea inicial era maior que a técnica da janela lateral para lado esquerdo. Em relação ao ganho de altura óssea, a abordagem da janela lateral pode aumentar a altura vertical do osso para mais de $9 \mathrm{~mm}$, a depender do descolamento da membrana e da quantidade de biomaterial inserida, enquanto na abordagem com osteótomos normalmente obtém-se uma menor elevação (AL-DAJANI M, 2014).

Uma revisão sistemática concluiu que o levantamento de seio é eficaz em ambas as técnicas apresentadas. Em um estudo, cujo osso residual disponível foi em média 6,4 mm, variando de 4,1 a 8,6 mm, as taxas de sobrevida variaram de $97,3 \%$ a $100 \%$ para o grupo com abordagem traumática e de $97,7 \%$ a $100 \%$ para o grupo com abordagem atraumática, sem diferença significativa entre os dois tratamentos (CORBELLA S, et al., 2015).

Cruz RS, et al. (2018) mostraram que o aumento do seio maxilar, realizado pela técnica da janela lateral ou pela técnica de Summers, apresenta resultados favoráveis quanto à sobrevida dos implantes. Outro trabalho também relatou uma alta taxa de sobrevivência do implante, maior de $96 \%$ após 5 anos com a abordagem mediada por osteótomos e sem utilização de material de enxerto (TASCHIERI S, et al., 2012).

O uso de enxerto ósseo no procedimento de elevação do seio maxilar não é obrigatório. Foi descrita na literatura a técnica de elevação do seio maxilar pela janela lateral sem enxerto tendo resultados previsíveis, baixa morbidade e taxa de sucesso esperada maior que $90 \%$ para implantes instalados na região posterior 
da maxila em médio e longo prazo. Em condições de elevações sinusais com enxerto ósseo e instalação de implantes, autores mostraram índice de sobrevivência de 98\% (PARRA M, et al., 2018).

Os diferentes biomateriais disponíveis apresentam comportamentos biológicos variados de acordo com sua origem, forma, tamanho, porosidade e taxa de degradação, podendo influenciar a taxa e o tempo de formação do osso, adesão e proliferação celular sobre o biomaterial (CHIPAILA N, et al., 2014; TASCHIERI S, et al., 2012; RAJA SV, 2009; SILVA LD, et al., 2016).

A forma, o tamanho e a aspereza da superfície das partículas influenciam na adesão e proliferação celular sobre o material. Quanto maior a porosidade dos grânulos do biomaterial, mais rápida será a dissolução do biomaterial. Outra característica a ser considerada é quanto a classificação dos biomateriais de acordo com a sua origem: autógenos (derivados do mesmo indivíduo), alógenos (derivados de indivíduos da mesma espécie), xenógenos (derivados de espécies diferentes) e aloplásticos (originados sinteticamente) (RAJA SV, 2009; SILVA LD, et al., 2016).

O enxerto autógeno é considerado o padrão ouro para reconstrução de processos alveolares atróficos por ter as qualidades de osteogênese, osteoindução e osteocondução (CARA-FUENTES M, et al., 2016). Entretanto, com o objetivo de reduzir a morbidade dos procedimentos cirúrgicos, a procura por substitutos que apresentassem as mesmas propriedades que o osso autógeno estimulou o desenvolvimento de materiais sintéticos. O material de enxertia Bio-Oss ${ }^{\circledR}$ (Geistlich Biomaterials, Wolhuser, Suíça) é um enxerto do tipo sintético particulado que traz em sua fórmula a hidroxiapatita sintética em uma estrutura altamente porosa, caracterizado por oferecer muito espaço para a angiogênese e osteogênese, propiciando sua substituição gradual por tecido ósseo e uma regeneração óssea adequada (CARA-FUENTES M, et al., 2016; RAGUCCI G, et al., 2019; CRUZ R, et al., 2018).

Outro aspecto a ser observado na seleção do substituto ósseo é a capacidade de ser ou não absorvido pelo organismo. Quanto a esse quesito, podem ser classificados em não absorvíveis, quando não sofrem processo de absorção e incorporação ao organismo receptor, permanecendo inertes, e em absorvíveis, quando são absorvidos pelo organismo receptor, com a substituição gradual por novo osso (CARA-FUENTES M, et al., 2016).

Em ambas as técnicas, existem possíveis complicações, sendo as mais comuns: perfuração da membrana de Schneider, migração do implante para o interior do seio maxilar e sangramento excessivo (CHIPAILA N, et al., 2014; ABI NAJM S, et al 2013; ROMERO-MILLÁN J, et al., 2018). Porém, tais intercorrências podem ser evitadas na medida em que fatores importantes como a identificação das estruturas anatômicas, os princípios fisiológicos de cicatrização dos tecidos e o manejo cirúrgico sejam de pleno conhecimento do cirurgião-dentista (AL-DAJANI M, 2014; ZHOU X, et al., 2017; KUMAR M, et al., 2018; RAGUCCI G, et al., 2019).

O risco de perfurações da membrana sinusal durante o procedimento de levantamento do seio maxilar é menor na técnica dos osteótomos do que àquelas relatadas para a técnica traumática (AL-DAJANI M, 2014; RAGUCCI G, et al., 2019). Nesse contexto, a osteotomia piezolétrica reduz notavelmente o risco de perfuração da membrana de Schneider, já que os instrumentos usados nessa osteotomia e elevação do seio são menos agressivos e mantêm o mínimo contato físico com membrana.

A vantagem da piezocirurgia está em trabalhar com microvibração de cinzéis à frequência ultrassônica, garantindo grande precisão e segurança durante a osteotomia. Assim, a associação da osteotomia piezolétrica e o levantamento do seio maxilar visa simplificar a abordagem do osteótomo, permitindo a elevação adequada do seio maxilar, a redução das complicações transoperatórias, além de minimizar o desconforto do paciente (AL-DAJANI M, 2014; KUMAR M, et al., 2018; RAGUCCI G, et al., 2019).

O levantamento do seio maxilar, seja pela técnica da janela lateral, seja pela técnica do osteótomo transcrestal, associado à instalação imediata de implantes osseointegrados é uma opção terapêutica eficaz, bem documentada e altamente previsível para a reabilitação da maxila posterior atrófica. Ademais, a anamnese adequada e o correto diagnóstico são fundamentais para a indicação da conduta cirúrgica mais apropriada, e, consequentemente, para o sucesso do tratamento. O plano de tratamento corresponderá às 
necessidades da área a ser tratada e, assim, saber identificar e respeitar a anatomia e os limites da região posterior maxilar é indispensável para a escolha da técnica cirúrgica, bem como para a redução do risco de falhas durante o procedimento cirúrgico.

\section{REFERÊNCIAS}

1. $A B I$ NAJM S, et al. Potential adverse events of implants penetrating the maxillary sinus: A prospective clinical study. Laryngoscope. 2013; 123(12): 2958-2961.

2. AL-DAJANI M. Recent Trends in Sinus Lift Surgery and Their Clinical Implications. Clin Implant Dent Relat Res. 2014; 18(1): 204-212.

3. BASSI AP, et al. Maxillary sinus lift without grafting, and simultaneous implant placement: a prospective clinical study with a 51-month follow-up. Int J Oral Maxillofac Surg. 2015; 44(7): 902-907.

4. CARA-FUENTES M, et al. Long-term outcome of dental implants after maxillary augmentation with and without bone grafting. Med Oral Patol Oral Cir Buccal. 2016;1(21):e229-e235.

5. CHIPAILA N, et al. Graftless sinus augmentation technique with contextual placement of implants: a case report. J Med Case Rep. 2014; 8(437): 1-11.

6. CORBELLA S, et al. Long-term outcomes for the treatment of atrophic posterior maxilla: a systematic review of literature. Clin Implant Dent Relat Res. 2015; 17(1): 120-132.

7. CRUZ R, et al. Short implants versus longer implants with maxillary sinus lift. A systematic review and meta-analysis. Braz Oral Res. 2018; 32: e86-e100.

8. KUMAR M, et al. Direct maxillary sinus floor augmentation for simultaneous dental implant placement. Ann Maxillofac Surg. 2018; 8(2): 188-192.

9. PARRA M, et al. Graftless Maxillary Sinus Lift Using Lateral Window Approach. Implant Dentistry. 2018; 27(1): 111118.

10. RAGUCCI G, et al. Influence of exposing dental implants into the sinus cavity on survival and complications rate: a systematic review. Int J Implant Dent. $2019 ; 5(1): 1-9$.

11. RAJA SV. Management of the posterior maxilla with sinus lift: review of techniques. J Oral Maxillofac Surg. 2009; 67(8): 1730-1734.

12. ROMERO-MILLÁN J, et al. Simultaneous and delayed direct sinus lift versus conventional implants: Retrospective study with 5-years minimum follow-up. Med Oral Patol Oral Cir Buccal. 2018; 23(6): e752-760.

13. SILVA LD, et al. Maxillary sinus lift surgery - with or without graft material? A systematic review. Int J Oral Maxillofac Surg. 2016; 45(12): 1570-1576.

14. TASCHIERI S, et al. Osteotome-Mediated Sinus Lift without Grafting Material: A Review of Literature and a Technique Proposal. Int J Dent. 2012; 2012:849093.

15. ZHOU X, et al. Minimally Invasive Crestal Sinus Lift Technique and Simultaneous Implant Placement. Chin J Dent Res. 2017; 20(4): 211-218. 